\title{
Stakeholders' opinions and questions regarding the anticipated malaria vaccine in Tanzania
}

\author{
Sally Mtenga ${ }^{1 *}$, Angela Kimweri ${ }^{1}$, Idda Romore ${ }^{1}$, Ali Ali ${ }^{1}$, Amon Exavery ${ }^{1}$, Elisa Sicuri ${ }^{2,3}$, Marcel Tanner ${ }^{5}$,
} Salim Abdulla', John Lusingu ${ }^{4}$ and Shubi Kafuruki ${ }^{1}$

\begin{abstract}
Background: Within the context of combined interventions, malaria vaccine may provide additional value in malaria prevention. Stakeholders' perspectives are thus critical for informed recommendation of the vaccine in Tanzania. This paper presents the views of stakeholders with regards to malaria vaccine in 12 Tanzanian districts.

Methods: Quantitative and qualitative methods were employed. A structured questionnaire was administered to 2123 mothers of under five children. Forty-six in-depth interviews and 12 focus group discussions were conducted with teachers, religious leaders, community health workers, health care professionals, and scientists. Quantitative data analysis involved frequency distributions and cross tabulations using Chi square test to determine the association between malaria vaccine acceptability and independent variables. Qualitative data were analysed thematically.

Results: Overall, $84.2 \%$ of the mothers had perfect acceptance of malaria vaccine. Acceptance varied significantly according to religion, occupation, tribe and region $(p<0.001)$. Ninety two percent reported that they will accept the malaria vaccine despite the need to continue using insecticide-treated nets (ITNs), while $88.4 \%$ reported that they will accept malaria vaccine even if their children get malaria less often than non-vaccinated children. Qualitative results revealed that the positive opinions towards malaria vaccine were due to a need for additional malaria prevention strategies and expectations that the vaccine will reduce visits to the health facility, deaths, malaria episodes and treatment-related expenses. Vaccine related questions included its side effects, efficacy, protective duration, composition, interaction with other medications, provision schedule, availability to the pregnant women, mode of administration (oral or injection?) and whether a child born of HIV virus or with a chronic illness will be eligible for the vaccine?

Conclusion: Stakeholders had high acceptance and positive opinions towards the combined use of the anticipated malaria vaccine and ITNs, and that their acceptance remains high even when the vaccine may not provide full protection, this is a crucial finding for malaria vaccine policy decisions in Tanzania. An inclusive communication strategy should be designed to address the stakeholders' questions through a process that should engage and be implemented by communities and health care professionals. Social cultural aspects associated with vaccine acceptance should be integrated in the communication strategy.
\end{abstract}

Keywords: Stakeholders, Opinions, Malaria vaccine, Tanzania, Questions

\section{Background}

Malaria remains a major public health concern in subSaharan Africa (SSA). Tanzania is one of the countries

\footnotetext{
*Correspondence: smtenga@ihi.or.tz

${ }^{1}$ Ifakara Health Institute (IHI), P.O. Box 78373, Dar es Salaam, Tanzania

Full list of author information is available at the end of the article
}

in which malaria continues to be a significant cause of morbidity, mortality and considered as an impediment to social economic growth and welfare [1]. According to the National Malaria Control Programme (NMCP), $90 \%$ of the Tanzanian population are at risk of malaria, resulting into 11 million clinical cases per year. The most vulnerable to malaria are children and pregnant mothers [2]. In 
Tanzanian mainland, the number of malaria microscopically-confirmed cases are 1,550,250 and reported deaths are 8525 [3]. Despite a declining trend in the number of admissions and deaths over the last few years, the country experiences a marked variation across regions having some with high malaria prevalence and others with low prevalence. For instance, there are regions with one percent or less and others with more than $30 \%$ [4]. The current malaria interventions in Tanzania include malaria testing by microscopy and/or rapid diagnostic tests, treatment with affordable and effective malaria treatment, such as artemisinin-based combination therapy $(\mathrm{ACT})$, protection using long-lasting insecticide-treated nets and indoor residual spraying with insecticides, intermittent preventive therapy with sulfadoxine-pyrimethamine for pregnant women [2]. However, challenges are also reported on existing malaria interventions with regards to resistance of malaria parasites to ACT, as well as non-use of mosquito nets $[5,6]$. Considering variations in malaria prevalence and challenges related to the existing malaria interventions, more innovative response including the vaccines to prevent malaria is likely to improve the impact of available interventions.

Vaccines are considered effective interventions in protecting individuals from infectious diseases and the best tool to achieving disease eradication in various contexts [7]. The currently most advanced candidate vaccine RTS, S/AS01 against Plasmodium falciparum malaria, has been tested across several sub-Saharan African countries including Tanzania. Phase 3 trials showed that during 12 months of follow-up, half malaria episodes were protected in 5-17 months. One third malaria episodes were protected in 6-12 weeks cohort [8]. In infants 6-12 weeks of age, vaccine efficacy was about $30 \%$ against both for clinical and severe malaria [9]. Recent study indicates that during 18 months of follow up, vaccination of children and young infants with RTS, S/AS01 prevented many cases of clinical and severe malaria and that the vaccination showed the highest impact in regions with the highest incidence of malaria [10]. Tanzania with other countries in Africa is underway to launch a malaria vaccine which is hoped to cut episodes of clinical malaria in young children by about half [11]. In the context of the current efficacy results a policy recommendation is likely to occur paving a way for the implementation of the vaccine in countries through their expanded programmes on immunization.

Although stakeholders' (community and professionals) voice is imperative before policy endorsement [12]; to date, there is limited information regarding their acceptance and questions related to the vaccine. Where information on the acceptance of the malaria vaccine exists $[13,14]$, it is not incorporated within the context of the ongoing malaria interventions and does not highlight on whether people may be willing to undertake the vaccine even when it is unlikely to provide full protection. Moreover, the accounts of contextual aspects that influence vaccine acceptance are not fully presented. Such information is crucial for policy decisions and future implementation if recommendation on the vaccine is made in the near future. However such information is missing in Tanzania despite being one of the country in which the RTS, S/AS01 vaccine trial was implemented. Experience indicates that it takes time for the interventions to gain public acceptance even after it has been licensed due to various factors including community acceptance and inadequate prior information that could inform the policy makers on what need to be considered before the implementation of the intervention [14]. Also, the absence of critical data could slow down the decision process that policymakers must undertake to determine whether or not to introduce a particular intervention into their health systems [15]. In addition, lack of community support due to poor knowledge and perceptions made community delay the uptake while others reject vaccines. For instance, it existed when Polio vaccination programme was delayed in northern Nigeria [16]. Therefore, it is crucial that community perceptions are understood and used to highlight any community-based issues that need to be considered during policy deliberation and intervention planning [17].

Within the context of planning for a vaccine to be used alongside existing malaria control methods, mothers of children under five and other stakeholders (teachers, religious leaders, community health workers, health care professionals and scientists) were interviewed to assess their perceptions on malaria and acceptance of the malaria vaccine.

The following were the specific objectives:

- To determine stakeholders' acceptance of the anticipated malaria vaccine and the associated factors.

- To assess stakeholders' perception and attitude towards the vaccines.

- To explore stakeholders' expectations from the anticipated malaria vaccine.

- To explore stakeholders' questions with regards to the anticipated malaria vaccine.

We hope that the study findings may assist the policy makers in Tanzania to make informed decisions on the introduction of malaria vaccine in line with other existing malaria intervention strategies [15]. The data may also inform the design of the communication strategy and guide the country's programmers on the issues to be considered before the actual implementation of the vaccine. 


\section{Methods}

\section{Overall study design}

A cross sectional study that involved quantitative and qualitative methods was conducted. The study was implemented between May and June 2013 in twelve districts of Tanzanian mainland (Table 1). The mixed method approach aimed at triangulating the methods and findings for completeness of the data [18]. The participating districts were from areas where phase II and III RTS, S malaria vaccine trial had not been implemented. This was done purposely to minimize bias of opinion with regards to acceptance of malaria vaccine. The districts were from the northern, eastern, western, central and southern parts of the country for enhancing the representativeness of voices from communities of diverse background since the future malaria vaccine may not only be introduced in trial sites. Malaria in the study regions ranges from $1 \%$ in Arusha to more than $20 \%$ in Lindi and Mtwara [1]. In the country, EPI coverage is high but varies across regions having the highest coverage in Arusha (100\%) and the lowest coverage in Kagera (57 \%) [19]. The health care system in Tanzania is composed of the public hospitals and the private hospitals. Hospitals are the highest level of access to care and the dispensary being the lowest level. However, at the dispensaries is where the majority of people in urban and rural communities access their health care.

\section{Qualitative methods \\ Design and setting}

Using qualitative approach, the study employed parallel individual interviews (IDIs) and focus groups discussions (FGDs). Qualitative participants were from some of the study sites where the quantitative study was conducted including participants from Mwanza (Ilemela district), Mbeya (Ileje district) and Arusha (Ngorongoro district). Addition participants were from Morogoro and Dar es

\section{Table 1 Study regions and the selected districts}

\begin{tabular}{ll}
\hline Regions & Districts \\
\hline Arusha & Ngorongoro \\
Tanga & Handeni \\
Kagera & Ngara \\
Pwani & Kisarawe \\
Mtwara & Newala \\
Mbeya & Ileje \\
Mara & Serengeti \\
Lindi & Lindi rural \\
Mwanza & Ilemela \\
Morogoro & Morogoro Municipal/Kilombero \\
Dar es Salaam & Kinondoni \\
Dodoma & Dodoma Municipal \\
\hline
\end{tabular}

Salaam regions. Preference to conduct qualitative study in these sites was based on the convenience and cost.

\section{Study population and recruitment}

Forty six IDIs and 12 FGDs were conducted. The IDI participants comprised of primary school teachers, religious leaders, community health workers, health care professionals, and scientists. The scientists who participated in the discussion were from various professional backgrounds (sociologists, medical doctors, public health, epidemiologists) excluding those who were participating in the clinical trials. FGDs were carried on with men and women in the respective study sites. The FGDs allowed insights into general group norms on the vaccines and capturing varied views and questions with regards to the anticipated malaria vaccine. The IDIs involved individuals who were believed to be capable of providing personal opinions about malaria and the anticipated malaria vaccine. The participants in the local communities were purposively [20] selected by the assistance of the community leaders believed to be influential in decisions about health-seeking practice in their families and community at large. Scientists were recruited from various institutions both public and private. Selection of the scientists was mostly based on the convenience and availability of the individuals in their institutions. The health care professionals were recruited based on their assimilation with child care services i.e. working in the reproductive health unit and paediatric care.

\section{Data collection}

Focus group guide with open ended questions was used to collect FGD data, while a semi structured topic list was used to collect IDI data. Both tools addressed similar topics directly designed to address specific study objectives. The tools were adjusted according to the best fit of the study audience. Main topics included: perception about malaria status, perception about malaria vaccine, expectations from malaria vaccines, preferred modality of providing malaria vaccine and questions with regards to malaria vaccine. IDI and FGD tools were piloted for practicability. Experienced research assistants conducted the IDIs and FGDs. Prior to data collection experienced social scientists (SM, AK) provided training to the research assistants. The training familiarized them with the study objectives, status of malaria vaccine research, interview procedures and ethical aspects. The FGDs were made of up to 7-9 participants and composed of a moderator who facilitated the discussion and a note taker who assisted in taking notes. Both discussions and interviews were conducted in a place convenient to the study participants. To enhance freedom of discussion, women and men had separate discussion groups. The discussion 
sessions were conducted in Kiswahili, a Tanzania national language which is well understood and used commonly in the study area. Subject to participants' consent some data from interviews with communities were audio-taped but other data was put in the expanded notes [21]. The interviews and discussions lasted for $1 \mathrm{~h}$ and $30 \mathrm{~min}$ on average.

\section{Data analysis}

Audio-recorded data was transcribed verbatim for analysis. The transcripts and expanded notes were checked for completeness and accuracy. Two social scientists (SA and AK) experienced in qualitative studies independently reviewed the transcripts to identify the relevant patterns and later the patterns were grouped into main themes. N-VIVO program [22] assisted in the display of participants expressions and the coding process. Considering the views of various stakeholders, a constant comparison approach was employed to compare themes that emerged from these analytic procedures [23]. To consolidate results, the identified themes and categories were shared in a malaria vaccine working groups and during the national stakeholders' meeting.

The stakeholders from immunization department in Tanzania and others discussed the findings and the consensus was reached about the interpretation of the results. All data were analysed in the Kiswahili but relevant quotes were translated into English for the purpose of this paper.

\section{Quantitative methods}

The study involved face to face household interviews with women aged 18 years and above, who had at least one child under 5 years. Quantitative study was employed to estimate level of acceptance of the malaria vaccine and preferred modality of providing malaria vaccine. The structured questionnaire was used to interview the eligible mothers. Before the interviews, the tools were piloted and later necessary changes were adopted in the tools.

A multi-stage random sampling was used to select the households in the specific study areas. At first the country was stratified based on regions, one region was randomly selected from which a list of districts was sought and then one district was randomly selected from the list of districts, (excluding the two districts that have been involved in malaria vaccine trial that is Bagamoyo and Korogwe), followed by village, and lastly household. The sample size was calculated based on simple random sampling given by the following formula and values attributed to parameters:

$$
n=\frac{Z^{2} p(1-p) N}{d^{2(N-1)+Z^{2} p(1-p)}}
$$

$\mathrm{n}=$ sample size; $\mathrm{z}$-score, which is the number of standard deviations from the mean. At $95 \%$ confidence level, $\mathrm{z}=1.96 ; \mathrm{p}=$ prevalence of malaria (assumed to be $50 \%$ ); $\mathrm{d}=$ absolute precision required $(1 \%) ; \mathrm{N}=$ population size (different according to the region, ranging from 188 to 332).

Thereafter, the sample size from simple random sample was multiplied by design effect to take into account the clustering effect. The design effect is given by:

$$
\text { Def }=1+(\text { Average population per cluster }-1) \times \rho
$$

where, $\rho$ is a cluster correlation. The sample size was required to detect $50 \%$ proportion on perception of malaria vaccine. The sample size calculation was to give idea of how many individuals were deemed to be interviewed from each study district. Prior to data collection, the research team received orientation on the purpose of the study, reminded about ethical aspects and review of the questions. Electronic devises (tablets) were used to collect information during the interviews, and later the information was synchronized into the field computers. Quality check and errors were carried out in the field and prompt feedback was provided to the field supervisors and later to the research assistants for corrective measures.

All the quantitative data were managed and analysed using STATA 11 Software (Stata corp, USA). Data analysis was performed as both one-way frequency distributions and cross tabulations of various outcomes against selected independent variables. In the latter case, Chi Square $\left(x^{2}\right)$ was used to test the degree of association between each pair of categorical variables involved in a cross-tabulation. The significance was determined at $p \leq 0.05$. Acceptability of the anticipated malaria vaccine was the main variable and was defined by three questions;

(A) Researchers are working to develop a malaria vaccine, which will have the possibility of reducing the recurrence of malaria among children. If the malaria vaccine becomes available will you be willing for your child to receive that malaria vaccine?

(B) Malaria vaccine may cause discomfort similar to other childhood vaccines will you agree or disagree that your child still get vaccinated?

(C) Even though a child is vaccinated, s/he will still have to use ITNs and seek treatment if s/he has fever. Will you agree that your child get vaccinated?

Frequency distribution of responses in each of these questions ( $\mathrm{A}, \mathrm{B}$ and $\mathrm{C})$ was performed.

Then bivariate analysis of each question, independent of the other, was conducted to assess how each of these outcomes was related to background and 
non-background characteristics of the participants, such as age, education, religion and region. Finally, these variables were combined to form a single powerful indicator of acceptability, such that:

\section{Perception and attitude towards vaccines}

Qualitative participants (mostly women) possessed a positive opinion towards vaccines. They were in the opinion that the vaccines are important for the reduction of

$$
\text { Acceptance of malaria vaccine }= \begin{cases}\text { PERFECT } & \text { if } \mathrm{A}=\mathrm{YES} \text { and } \mathrm{B}=\mathrm{YES} \text { and } \mathrm{C}=\mathrm{YES} \\ \text { PARTIAL } & \text { if YES to any one or two but not all of the A, B and C } \\ \text { NO } & \text { if } \mathrm{A} \neq \mathrm{YES}\end{cases}
$$

\section{Ethical aspects}

The study was approved by the ethical review board of the Ifakara Health Institute (IHI-IRB). Prior to interviews, local authorities were contacted and asked for permission. Written consent to approach the study communities was obtained. Verbal and written informed consents were obtained from all study participants through which participants were assured of anonymity and confidentiality of information.

\section{Results}

Since the study was a mixed method design, results are triangulated for the purpose of elaboration and completeness. Results are presented in general themes emanated from the study objectives. Qualitative findings are not presented according to study groups due to observed convergence of views and opinions with regards study phenomenon.

\section{Characteristics of study respondents}

Out of a sample size of 2124, a total of 2123 mothers with children under five from nine districts participated in the study. Of the 2123 mothers, $70 \%$ were in the age range of 20 and 34 years. A majority of mothers $(84 \%)$ were in marital relations. Slightly more than one third (34.7\%) of the participants had more than three children. The study population was relatively literate with only $19.4 \%$ of respondents who had never attended school, whilst about $69.4 \%$ had attained primary school and $11 \%$ had secondary education. A majority (70.4\%) of respondents were farmers. About $56.2 \%$ of respondents were Christians and $40.9 \%$ were Muslims (Table 2).

Qualitative participants composed of 21 health care professionals (18 health care providers and four paediatricians), six teachers, four religious leaders and six community health workers. Twelve more IDIs were conducted with scientists from various institutions in Dar es Salaam (Table 3). FGDs were carried on with six groups of women and six groups of men. Most of the FGD and IDI participants were of age 25 and 50. Non-professional participants were mostly farmers and petty trade dealers. Most of them had attained primary school level. The majority of the professionals, such as nurses and teachers, were of secondary school and high school levels. disease severity, reduced cost of treatment and disease prevention.

One female participant expressed her opinion that vaccine would reduce the severity of disease:

"I know that when a child gets vaccinated he will be protected from diseases. Even if the disease comes, it will not be very much severe as compared to if the child has not completely received a vaccine" (FGD, Female_04).

Another female participant was in the opinion that vaccine is important for prevention of diseases:

"Just like what the experts says "it is better to prevent than to cure" then I think vaccination is important as it helps to prevent a child from diseases and reduces treatment costs because during treatment you use much cost to treat the child unlike when the child is protected (with the vaccine)" (FGD, Female_05).

Similarly in the quantitative study, the majority (90.1\%) of mothers reported that there is a benefit associated with vaccination (Fig. 1). Also, about $97.6 \%$ agreed with the statement that 'I prefer my child to receive all the vaccines' (Table 4).

\section{Acceptance of malaria vaccine and the associated reasons}

Most of the opinions of the qualitative participants reflected a positive acceptance towards the anticipated malaria vaccine. The main consensus was that malaria vaccine is important since malaria is still a common disease among children under five.

One of the paediatricians provided his view that malaria vaccine need to be provided since more strategies are needed to fight malaria:

"I think malaria problem is still there and more weapons are needed in making sure that it is prevented, vaccine is one of the weapon, but if it's safe for the users" (IDI, Paediatrician_05).

Another participant was in the opinion that malaria still affects children and hence a need to introduce malaria vaccine: 
Table 2 Characteristics of the respondents in 2013 household survey $(\mathbf{n}=\mathbf{2 1 2 3})$

\begin{tabular}{|c|c|c|}
\hline Characteristics & $\begin{array}{l}\text { Number of } \\
\text { respondents (n) }\end{array}$ & $\begin{array}{l}\text { Percent } \\
(\%)\end{array}$ \\
\hline Overall & 2123 & 100.0 \\
\hline \multicolumn{3}{|l|}{ Age (years) } \\
\hline$<20$ & 143 & 6.7 \\
\hline $20-34$ & 1499 & 70.6 \\
\hline$>34$ & 481 & 22.7 \\
\hline Mean $=28.9 \pm 7.6, \min =15.0, \max =65.0$ & - & - \\
\hline \multicolumn{3}{|l|}{ Marital status } \\
\hline Currently married & 1793 & 84.5 \\
\hline Ever married (currently divorced/widowed) & 143 & 6.7 \\
\hline Single & 187 & 8.8 \\
\hline \multicolumn{3}{|l|}{ Education } \\
\hline Never been to school & 412 & 19.4 \\
\hline Primary & 1473 & 69.4 \\
\hline Secondary+ & 238 & 11.2 \\
\hline \multicolumn{3}{|l|}{ Parity (number of children) } \\
\hline 1 & 537 & 25.3 \\
\hline 2 & 473 & 22.3 \\
\hline 3 & 376 & 17.7 \\
\hline $4+$ & 737 & 34.7 \\
\hline \multicolumn{3}{|l|}{ Occupation } \\
\hline Farmer/other & 1495 & 70.4 \\
\hline Business (petty vender, tailoring etc) & 355 & 16.7 \\
\hline Housekeeper/no job & 215 & 10.1 \\
\hline Civil servant & 58 & 2.7 \\
\hline \multicolumn{3}{|l|}{ Religion } \\
\hline Islam & 868 & 40.9 \\
\hline Christian & 1192 & 56.2 \\
\hline Other & 63 & 3.0 \\
\hline \multicolumn{3}{|l|}{ Tribe } \\
\hline Kurya & 313 & 14.7 \\
\hline Makonde & 272 & 12.8 \\
\hline Hangaza & 206 & 9.7 \\
\hline Zigua & 204 & 9.6 \\
\hline Zaramo & 140 & 6.6 \\
\hline Ndali & 129 & 6.1 \\
\hline Sukuma & 120 & 5.7 \\
\hline Others $^{a}$ & 739 & 34.8 \\
\hline \multicolumn{3}{|l|}{ Region (district) } \\
\hline Arusha (Ngorongoro) & 280 & 13.2 \\
\hline Kagera (Ngara) & 331 & 15.6 \\
\hline Lindi (Lindi rural) & 183 & 8.6 \\
\hline Mara (Serengeti) & 286 & 13.5 \\
\hline Mbeya (Ileje) & 188 & 8.9 \\
\hline Mtwara (Newala) & 193 & 9.1 \\
\hline Mwanza (Ilemela) & 235 & 11.1 \\
\hline Pwani (Kisarawe) & 190 & 9.0 \\
\hline Tanga (Handeni) & 237 & 11.2 \\
\hline
\end{tabular}

a Sonjo, Mwela, Yao, Iraki, Chagga, Ha, Masai, Haya, Zigua, Sambaa etc
Table 3 Summary of the IDIs and FGDs participants

\begin{tabular}{|c|c|c|}
\hline & Further details & $\begin{array}{l}\text { Total number } \\
\text { of participants }\end{array}$ \\
\hline \multicolumn{3}{|l|}{ IDIs } \\
\hline \multicolumn{3}{|c|}{ Health care professionals } \\
\hline Nurses & $\begin{array}{l}\text { From public health facilities } \\
\text { and private health facilities }\end{array}$ & 12 \\
\hline Paediatricians & From public health facilities & 3 \\
\hline Paediatricians & From private health facilities & 3 \\
\hline Teachers & From rural community & 6 \\
\hline Religious leaders & From Muslim community & 2 \\
\hline Religious leaders & From Christian community & 2 \\
\hline $\begin{array}{l}\text { Community } \\
\text { health workers }\end{array}$ & From rural community & 6 \\
\hline Scientists & $\begin{array}{l}\text { From sociological back- } \\
\text { ground }\end{array}$ & 3 \\
\hline Scientists & From medical background & 3 \\
\hline Elites & $\begin{array}{l}\text { From government and } \\
\text { private institutions }\end{array}$ & 6 \\
\hline Total & & 45 \\
\hline \multicolumn{3}{|l|}{ FGDs } \\
\hline Women & From rural community & 6 \\
\hline Men & From rural community & 6 \\
\hline Total & & 12 \\
\hline
\end{tabular}

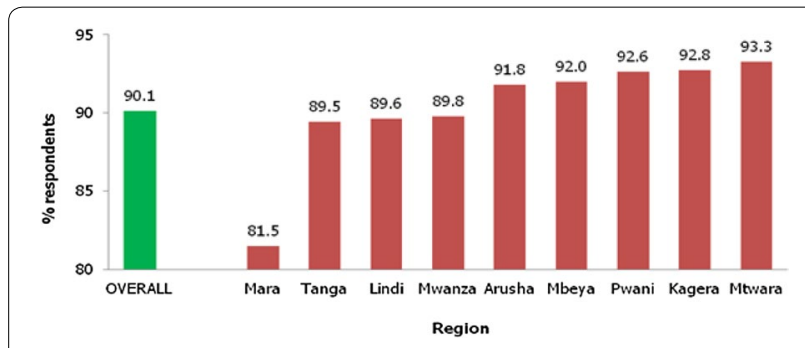

Fig. 1 Percent distribution of respondents that believe that there are benefits related to under-five child vaccination $(n=2123)$

"Malaria vaccine should be introduced due to the burden of malaria especially for young children" (IDI, Nurse, RCH_06).

A male participant thought that malaria vaccine is needed because the mosquito nets cannot provide full protection from mosquitoes:

"I think we need malaria vaccine since we are not always covered by the mosquito nets. Look at where we are now, we have stayed for almost one hour and the mosquito nets are inside our houses on the beds. Probably the mosquitoes might have already bitten the child. Therefore, we cannot totally depend on the mosquito nets..." (FGD, Male_05). 
Table 4 Perception towards vaccine: percent distribution of respondents that AGREE with the listed statements by region $(n=2123)$

\begin{tabular}{|c|c|c|c|c|}
\hline & \multirow{2}{*}{$\begin{array}{l}\text { Number } \\
\text { of respond- } \\
\text { ents }\end{array}$} & \multicolumn{3}{|c|}{$\%$ Stated that ... } \\
\hline & & $\begin{array}{l}\text { I prefer my } \\
\text { child to } \\
\text { have all } \\
\text { vaccinations }\end{array}$ & $\begin{array}{l}\text { I prefer my } \\
\text { child to have } \\
\text { certain } \\
\text { vaccinations }\end{array}$ & $\begin{array}{l}\text { I prefer my } \\
\text { child not } \\
\text { to be } \\
\text { vaccinated } \\
\text { at all }\end{array}$ \\
\hline Overall & 2123 & 97.6 & 0.7 & 0.1 \\
\hline \multicolumn{5}{|l|}{ Region } \\
\hline Arusha & 280 & 98.2 & 1.1 & 0.4 \\
\hline Kagera & 331 & 98.8 & 0.0 & 0.0 \\
\hline Lindi & 183 & 97.3 & 1.6 & 0.0 \\
\hline Mara & 286 & 99.0 & 1.4 & 0.0 \\
\hline Mbeya & 188 & 100.0 & 0.0 & 0.0 \\
\hline Mtwara & 193 & 97.9 & 0.0 & 0.0 \\
\hline Mwanza & 235 & 98.7 & 0.9 & 0.0 \\
\hline Pwani & 190 & 91.6 & 0.0 & 0.0 \\
\hline Tanga & 237 & 94.9 & 0.8 & 0.0 \\
\hline
\end{tabular}

The quantitative results revealed that the majority $(84.2 \%)$ of the participants indicated a perfect acceptance of malaria vaccine, $11.9 \%$ had partial acceptance while $3.9 \%$ had no acceptance of the vaccine (Table 5). Occupation, tribe, religion, and regions attained a statistical significance with the perfect acceptance of the malaria vaccine ( $<<0.001)$, with farmers, Christians, members of the tribe Hangaza and households in the Kagera region presenting higher acceptance levels.

\section{Expectations from malaria vaccine}

The common expectations from the malaria vaccine by most participants comprised a view that malaria vaccine will lessen the malaria episodes, frequent visits to the hospital due to malaria, the number of deaths and that the overall burden of malaria among children will be reduced.

"My expectations is that if malaria vaccine will work, it will help reduce the hassle we get of having frequent malaria, you will find a child going back to hospital even four times in a month" (FGD, Male _03).

"The expectations of most people will be that the malaria vaccine will completely eradicate malaria, because the children will have protection...and so malaria will finish...” (FGD, Female_05).

"The health care providers will feel very proud to have this additional vaccine on top of the existing ones since we hope it will succeed in reducing the mortality rate especially for children under 5 years" (Nurse, RCH_05).

"Most mothers will definitely take their kids for vaccination since the costs of treatment nowadays is very high" (Teacher_02).

\section{Acceptance of malaria vaccine in the context of ITN use} The majority (92.5\%) reported that they will be ready to take their children for malaria vaccine despite their obligation to use ITNs and seek treatment when the child has fever. There were differences in the level of acceptance across regions, religion and tribe. The Mbeya region was more likely to indicate acceptance comparatively to other study regions $(\mathrm{p}=0001)$ (Table 6$)$.

\section{Acceptance of malaria vaccine in the context of partial protection}

Participants were asked to provide their views on how they think about accepting the forthcoming malaria vaccine despite that their children will get malaria less often than those who don't get the vaccine. Most participants views consistently indicated a willingness to uptake malaria vaccine in the context of its partial protection due to their concern with the burden of malaria and the view that the less the episodes the less the cost of treatment.

"This malaria vaccine need to be introduced because
it will reduce the magnitude of malaria, even if it
reduces to some extent, it is still important, because
if a child gets malaria less frequently different from
now, the costs of treatment will reduce..." (IDI, Reli-
gious leader_02).

"If efficacy is $50 \%$ is fine as long as you have helped the person by reducing the episodes. This will help to enhance immunity" (IDI, Health professional lecturer_04).

"Vaccine would be the best solution, even if it is partially protected then should be introduced. It should go parallel with other strategies to be more effective." (IDI_Paediatrician_3).

"... even with existing vaccines, still the children get sick but not as much as those who did not get vaccine at all" (Teacher_03).

The views of the qualitative participants converged with the quantitative data which indicated that the majority of mothers $(88.4 \%)$ reported that they will be 
Table 5 Degree of malaria vaccine acceptability by various characteristics $(n=2123)$

\begin{tabular}{|c|c|c|c|c|c|}
\hline \multirow[t]{2}{*}{ Characteristics } & \multirow{2}{*}{$\begin{array}{l}\text { Total number } \\
\text { of respondents }\end{array}$} & \multicolumn{3}{|c|}{ Degree of acceptability (\%) } & \multirow[t]{2}{*}{$P$ value } \\
\hline & & Perfect acceptance & Partial acceptance & No acceptance & \\
\hline Overall & 2123 & 84.2 & 11.9 & 3.9 & - \\
\hline \multicolumn{6}{|l|}{ Age (years) } \\
\hline$<20$ & 143 & 83.9 & 14.0 & 2.1 & \multirow[t]{3}{*}{0.466} \\
\hline $20-34$ & 1499 & 83.6 & 12.3 & 4.1 & \\
\hline$>34$ & 481 & 86.1 & 10.2 & 3.7 & \\
\hline \multicolumn{6}{|l|}{ Marital status } \\
\hline Currently married & 1793 & 84.5 & 11.4 & 4.1 & \multirow[t]{3}{*}{0.149} \\
\hline Ever married (currently divorced/widowed) & 143 & 79.7 & 18.2 & 2.1 & \\
\hline Single & 187 & 84.5 & 11.8 & 3.7 & \\
\hline \multicolumn{6}{|l|}{ Education } \\
\hline Never been to school & 412 & 87.4 & 10.2 & 2.5 & \multirow[t]{3}{*}{0.136} \\
\hline Primary & 1473 & 83.9 & 12.0 & 4.1 & \\
\hline Secondary+ & 238 & 80.3 & 14.3 & 5.5 & \\
\hline \multicolumn{6}{|l|}{ Parity (number of children) } \\
\hline 1 & 537 & 81.8 & 14.3 & 3.9 & \multirow[t]{4}{*}{$<0.169$} \\
\hline 2 & 473 & 82.0 & 13.5 & 4.4 & \\
\hline 3 & 376 & 85.6 & 10.1 & 4.3 & \\
\hline $4+$ & 737 & 86.6 & 10.0 & 3.4 & \\
\hline \multicolumn{6}{|l|}{ Occupation } \\
\hline Farmer/other & 1495 & 86.1 & 10.5 & 3.4 & \multirow[t]{4}{*}{$<0.001$} \\
\hline Business (petty vender, tailoring etc) & 355 & 81.1 & 14.7 & 4.2 & \\
\hline Housekeeper/no job & 215 & 77.7 & 17.7 & 4.7 & \\
\hline Civil servant & 58 & 77.6 & 10.3 & 12.1 & \\
\hline \multicolumn{6}{|l|}{ Religion } \\
\hline Islam & 868 & 79.7 & 13.5 & 6.8 & \multirow[t]{3}{*}{$<0.001$} \\
\hline Christian & 1192 & 87.3 & 10.8 & 1.9 & \\
\hline Other & 63 & 87.3 & 11.1 & 1.6 & \\
\hline \multicolumn{6}{|l|}{ Tribe } \\
\hline Kurya & 313 & 87.5 & 10.9 & 1.6 & \multirow[t]{8}{*}{$<0.001$} \\
\hline Makonde & 272 & 79.8 & 16.5 & 3.7 & \\
\hline Hangaza & 206 & 93.7 & 4.9 & 1.5 & \\
\hline Zigua & 204 & 90.2 & 6.4 & 3.4 & \\
\hline Zaramo & 140 & 76.4 & 10.0 & 13.6 & \\
\hline Ndali & 129 & 90.7 & 8.5 & 0.8 & \\
\hline Sukuma & 120 & 80.8 & 15.8 & 3.3 & \\
\hline Others $^{\mathrm{a}}$ & 739 & 80.9 & 14.5 & 4.6 & \\
\hline \multicolumn{6}{|l|}{ Region (district) } \\
\hline Arusha (Ngorongoro) & 280 & 80.0 & 16.8 & 3.2 & \multirow[t]{9}{*}{$<0.001$} \\
\hline Kagera (Ngara) & 331 & 93.4 & 5.1 & 1.5 & \\
\hline Lindi (Lindi rural) & 183 & 78.1 & 16.4 & 5.5 & \\
\hline Mara (Serengeti) & 286 & 86.7 & 11.2 & 2.1 & \\
\hline Mbeya (Ileje) & 188 & 90.4 & 9.0 & 0.5 & \\
\hline Mtwara (Newala) & 193 & 79.8 & 16.1 & 4.2 & \\
\hline Mwanza (Ilemela) & 235 & 81.3 & 16.2 & 2.6 & \\
\hline Pwani (Kisarawe) & 190 & 72.1 & 15.8 & 12.1 & \\
\hline Tanga (Handeni) & 237 & 89.0 & 4.6 & 6.3 & \\
\hline
\end{tabular}

a Sonjo, Mwela, Yao, Iraki, Chagga, Ha, Masai, Haya, Sambaa etc 
Table 6 Percent distribution of respondents ready to get their children vaccinated with malaria vaccine despite the fact that even though a child is vaccinated, s/he will still have to use ITNs and seek treatment if $s / h e$ has fever; by various characteristics $(n=2123)$

\begin{tabular}{|c|c|c|c|}
\hline Characteristics & $\begin{array}{l}\text { Total number } \\
\text { of respondents }\end{array}$ & $\%$ Ready & $P$ value \\
\hline Overall & 2123 & 92.5 & - \\
\hline \multicolumn{4}{|l|}{ Age (years) } \\
\hline$<20$ & 143 & 93.7 & 0.798 \\
\hline $20-34$ & 1499 & 92.3 & \\
\hline$>34$ & 481 & 92.7 & \\
\hline \multicolumn{4}{|l|}{ Marital status } \\
\hline Currently married & 1793 & 92.5 & 0.742 \\
\hline $\begin{array}{l}\text { Ever married (cur- } \\
\text { rently divorced/ } \\
\text { widowed) }\end{array}$ & 143 & 90.9 & \\
\hline Single & 187 & 93.1 & \\
\hline \multicolumn{4}{|l|}{ Education } \\
\hline Never been to school & 412 & 92.5 & 0.962 \\
\hline Primary & 1473 & 92.5 & \\
\hline Secondary+ & 238 & 92.0 & \\
\hline \multicolumn{4}{|c|}{ Parity (number of children) } \\
\hline 1 & 537 & 93.1 & 0.446 \\
\hline 2 & 473 & 90.9 & \\
\hline 3 & 376 & 92.0 & \\
\hline $4+$ & 737 & 93.2 & \\
\hline \multicolumn{4}{|l|}{ Occupation } \\
\hline Farmer/other & 1495 & 93.1 & 0.125 \\
\hline $\begin{array}{l}\text { Business (petty } \\
\text { vender, tailoring } \\
\text { etc) }\end{array}$ & 355 & 90.7 & \\
\hline Housekeeper/no job & 215 & 92.6 & \\
\hline Civil servant & 58 & 86.2 & \\
\hline \multicolumn{4}{|l|}{ Religion } \\
\hline Islam & 868 & 88.5 & $<0.001$ \\
\hline Christian & 1192 & 95.1 & \\
\hline Other & 63 & 96.8 & \\
\hline \multicolumn{4}{|l|}{ Tribe } \\
\hline Kurya & 313 & 94.6 & $<0.001$ \\
\hline Makonde & 272 & 91.2 & \\
\hline Hangaza & 206 & 96.1 & \\
\hline Zigua & 204 & 94.1 & \\
\hline Zaramo & 140 & 82.1 & \\
\hline Ndali & 129 & 99.2 & \\
\hline Sukuma & 120 & 92.5 & \\
\hline Others $^{\mathrm{a}}$ & 739 & 91.3 & \\
\hline \multicolumn{4}{|l|}{ Region (district) } \\
\hline Arusha (Ngorongoro) & 280 & 92.1 & $<0.001$ \\
\hline Kagera (Ngara) & 331 & 96.7 & \\
\hline Lindi (Lindi rural) & 183 & 88.5 & \\
\hline Mara (Serengeti) & 286 & 93.7 & \\
\hline Mbeya (Ileje) & 188 & 99.5 & \\
\hline
\end{tabular}

Table 6 continued

\begin{tabular}{|c|c|c|c|}
\hline Characteristics & $\begin{array}{l}\text { Total number } \\
\text { of respondents }\end{array}$ & \% Ready & P value \\
\hline Mtwara (Newala) & 193 & 90.7 & \\
\hline Mwanza (Ilemela) & 235 & 93.6 & \\
\hline Pwani (Kisarawe) & 190 & 81.1 & \\
\hline Tanga (Handeni) & 237 & 92.4 & \\
\hline
\end{tabular}

a Sonjo, Mwela, Yao, Iraki, Chagga, Ha, Masai, Haya, Sambaa etc

comfortable that their children receive malaria vaccine despite that they will still get malaria less often than those who don't get the vaccine. Age of mothers, religion, region and tribes were statistically significantly associated with the acceptance of partial protection of malaria vaccine (Table 7).

\section{Questions regarding the anticipated malaria vaccines}

Despite a positive attitude towards the anticipated malaria vaccine, most participants had various questions with regards to the vaccine. However, there appeared to be similarities with regards to the questions asked by the communities and those asked by other professions. Most questions were mostly related to the side effects of the vaccine and the government response to them, efficacy, protective duration, composition, interaction with other medications, relation of vaccine schedule with existing EPI schedule, availability of the vaccine to the pregnant women, mode of administration (oral or injection?) and whether child born of HIV virus or with a chronic illness will be eligible for the vaccine? (Fig. 2).

\section{Discussion}

The study findings suggest that stakeholders have a positive attitude towards the anticipated malaria vaccine and that their acceptance of the vaccine remains high despite the fact that it would be used parallel with other existing intervention strategies. Interestingly, the acceptance level also remains significant though the malaria vaccine is less likely to provide full protection. This outcome could be a reflection of how malaria is seriously perceived in the communities being studied. Furthermore, they may be willing to accept the new malaria interventions as long as they will (to some extent) contribute to the reduction of malaria, especially among children. Similarly, a study in Kenya also found that participants understood that malaria is a serious problem that no single tool can be used to combat it, which influences their acceptance of malaria vaccine [14]. Acceptance of malaria vaccine was also observed in studies conducted in Ghana [13] where the views of various professions and communities also reflected a positive opinion towards the introduction of malaria vaccine as a preventive tool. The study finding 
Table 7 Percent distribution of respondents that answered "YES" to the question "If your child receives malaria vaccine, and still gets malaria but less often than those who don't get vaccine, will you be comfortable with that?"; by various characteristics $(n=2123)$

\begin{tabular}{|c|c|c|c|}
\hline Characteristics & $\begin{array}{l}\text { Total number } \\
\text { of respondents }\end{array}$ & $\begin{array}{l}\text { \% That would } \\
\text { be comfortable }\end{array}$ & $P$ value \\
\hline Overall & 2123 & 88.4 & - \\
\hline \multicolumn{4}{|l|}{ Age (years) } \\
\hline$<20$ & 143 & 83.2 & \multirow[t]{3}{*}{0.010} \\
\hline $20-34$ & 1499 & 87.9 & \\
\hline$\geq 34$ & 481 & 91.7 & \\
\hline \multicolumn{4}{|l|}{ Marital status } \\
\hline Currently married & 1793 & 88.7 & \multirow[t]{3}{*}{0.559} \\
\hline $\begin{array}{l}\text { Ever married (currently } \\
\text { divorced/widowed) }\end{array}$ & 143 & 86.7 & \\
\hline Single & 187 & 86.6 & \\
\hline \multicolumn{4}{|l|}{ Education } \\
\hline Never been to school & 412 & 87.9 & \multirow[t]{3}{*}{0.863} \\
\hline Primary & 1473 & 88.7 & \\
\hline Secondary+ & 238 & 87.8 & \\
\hline \multicolumn{4}{|l|}{ Parity (number of children) } \\
\hline 1 & 537 & 86.2 & \multirow[t]{4}{*}{0.253} \\
\hline 2 & 473 & 88.2 & \\
\hline 3 & 376 & 89.9 & \\
\hline $4+$ & 737 & 89.4 & \\
\hline \multicolumn{4}{|l|}{ Occupation } \\
\hline Farmer/other & 1495 & 88.8 & \multirow[t]{4}{*}{0.293} \\
\hline $\begin{array}{l}\text { Business (petty vender, } \\
\text { tailoring etc) }\end{array}$ & 355 & 88.5 & \\
\hline Housekeeper/no job & 215 & 84.7 & \\
\hline Civil servant & 58 & 91.4 & \\
\hline \multicolumn{4}{|l|}{ Religion } \\
\hline Islam & 868 & 85.0 & \multirow[t]{3}{*}{$<0.001$} \\
\hline Christian & 1192 & 90.7 & \\
\hline Other & 63 & 92.1 & \\
\hline \multicolumn{4}{|l|}{ Tribe } \\
\hline Kurya & 313 & 92.3 & \multirow[t]{8}{*}{$<0.001$} \\
\hline Makonde & 272 & 87.5 & \\
\hline Hangaza & 206 & 92.2 & \\
\hline Zigua & 204 & 92.2 & \\
\hline Zaramo & 140 & 74.3 & \\
\hline Ndali & 129 & 93.0 & \\
\hline Sukuma & 120 & 83.3 & \\
\hline Others $^{a}$ & 739 & 87.7 & \\
\hline \multicolumn{4}{|l|}{ Region (district) } \\
\hline Arusha (Ngorongoro) & 280 & 92.5 & \multirow[t]{6}{*}{$<0.001$} \\
\hline Kagera (Ngara) & 331 & 90.6 & \\
\hline Lindi (Lindi rural) & 183 & 84.2 & \\
\hline Mara (Serengeti) & 286 & 89.9 & \\
\hline Mbeya (Ileje) & 188 & 93.1 & \\
\hline Mtwara (Newala) & 193 & 88.6 & \\
\hline
\end{tabular}

Table 7 continued

\begin{tabular}{|c|c|c|c|}
\hline Characteristics & $\begin{array}{l}\text { Total number- } \\
\text { of respondents }\end{array}$ & $\begin{array}{l}\% \text { That would } \\
\text { be comfortable }\end{array}$ & P value \\
\hline Mwanza (Ilemela) & 235 & 89.4 & \\
\hline Pwani (Kisarawe) & 190 & 72.6 & \\
\hline Tanga (Handeni) & 237 & 89.9 & \\
\hline
\end{tabular}

that stakeholders would still maintain the acceptance of malaria vaccine in the context of existing malaria intervention strategies is in line with the overall idea of introducing the vaccine which is not meant to replace the existing malaria interventions but rather to compliment it [11].

In this study, social cultural aspects emerged as factors associated with the acceptance of malaria vaccine. These factors include religion (Christians were more willing than Muslims to accept the vaccine), religion (Ndali tribe was less willing to accept the vaccine than the other tribes), and civil servants were more willing to accept the vaccine than the farmers. This finding corroborates with evidence from other countries in Africa [24] and elsewhere [25] where religion and ethnicity were found to influence health care utilization. Specific evidence also indicates that religion and ethnicity are associated with vaccine awareness and acceptance i.e measles vaccine and Human Papillomavirus (HPV) [25, 26].

The differences in vaccine acceptance based on religion, ethnicity and occupation as observed in this study could also reflect that people's values, preferences and expectations would sometimes constrain their acceptance of a particular health care programme. These could originate from the culture in which the social interaction is taking place, which in turn govern their decisions about how they should pursue a recommended health intervention [27]. Although other studies have found that the quality of care i.e. congestion, delays, and the perceived attitudes of the health care providers [14], access to services, reliability of services fear of side effects, and parental beliefs and conflicting priorities [28] constraints immunization services, this study shows that in addition to individual and health system factors, the social cultural aspects may play a significant role in influencing the differential acceptance of vaccination programmes. This is central in this paper, and it lends support to the views of other researchers that people may not automatically use a health intervention once introduced [14], and in the context of a vaccine, if the known barriers are not addressed may lead to under-utilization of immunization coverage $[16,29]$. 


\section{Communities}

1. How many times will the children need to receive the vaccine?

2. Will the child born of HIV virus or with a chronic illness be allowed to receive a malaria vaccine?

3. Will the vaccine be available also for pregnant women?

4. What will be the schedule of providing a vaccine? Is it when the child gets malaria or...?.

5. The vaccine will be provided for which age?

6. How long will the vaccine take to expire in the body or will it be a lifelong vaccine?

7. Will the vaccine really protect children and not bring harm?

\section{Professions}

1. What will be the side effects of the vaccine?

2. Will the new clinic cards be issued? Or the information will be integrated within the existing cards?

3. How will the vaccine interact with other medications?

4. What will the providers do if the vaccines fail to work?

5. Will the vaccine have a booster dose?

6. Will it be given separately or in combination with the existing vaccines?

7. Will the vaccine completely protect children from malaria?

8. Will the nurses be trained for the new vaccine?

9. Will the vaccine be provided to adults?

8. Will the child need to continue using a mosquito net or the vaccine would have protected the child?

11. Which type of plasmodium does the vaccine target?

12. What will be the mode of administration? (given in

9. On what form will the vaccine be provided? Is it in liquid or injection? powder or liquid form?)

13. What will be the extent of it's risk?

10. If the vaccine becomes poisonous to children

14. What does the malaria vaccine compose? what will the government do to help the 15. What are the associated side effects? child?

Fig. 2 The common questions with regards to malaria vaccines by communities and professions

Currently there is a strong recognition globally that health is socially determined and that social-structural aspects are responsible for health inequity. As found in this study, religion and ethnicity may play a significant role towards inequity in immunization coverage. Health inequity is known to be a set back to the wider health development, and this could be addressed by examining the wider social and structural aspects that increase vulnerability to diseases [30-33]. Evidence in Nigeria indicates that the community tailored interventions have proven to be effective in increasing the utilization of polio vaccination [34]. As such, the public health communication strategy that seek to promote the available immunization services as well as the anticipated malaria vaccine could be made effective if tailored within the broader social aspirations and cultural differences existing in the locally contextualized environment.

This study also found that the community and other professionals have multiple expectations and questions that relate to the anticipated malaria vaccine. It is important that the Tanzanian Immunization
Department, malaria vaccine initiative, and other malaria stakeholders clarifies the questions and expectations prior to or parallel with the introduction of the malaria vaccine and provide the correct knowledge about the added value of malaria vaccine in lay man's language to avoid any misconceptions about the anticipated malaria vaccine. The voices of communities and that of the health care professionals are important and should be considered for better informed decisions, policy recommendation, planning and designing of a communication strategy. Failure to account for community's prior information that could enlighten policy makers on what is needed to be considered before the implementation of the intervention was found as one of the factors that could delay the public acceptance of the proposed intervention [14].

\section{Conclusions}

Understanding stakeholders' acceptability and perspectives regarding the anticipated malaria vaccine in the context of other ongoing malaria interventions is crucial for 
appropriate policy decisions in Tanzania. Stakeholders' high acceptability of the anticipated malaria vaccine, even when it is less likely to provide full protection may reflect the extent to which malaria interventions, are needed in the study areas. However the questions raised by the communities reflect the need to clarify some misconceptions and provision of correct knowledge regarding the vaccine. The optimal acceptance and utilization of the anticipated malaria vaccine may require addressing of the social cultural aspects that could impede the utilization of the vaccine.

\section{Key messages and recommendations}

The fact that the views of various community groups reflect a willingness to undertake malaria vaccine parallel with the existing malaria intervention strategies (such as ITNs) could be one of the strengths within the National Malaria Control Strategy in Tanzania. This aspect may need to be emphasized during the implementation phase of malaria vaccine, since the vaccine may not provide full protection. Communities are also ready to accept a partial efficacy malaria vaccine, which may be useful in guiding policy recommendations toward the vaccine in the country.

Although stakeholders possess a positive opinion towards the anticipated malaria vaccine there is much on which the Tanzanian Immunization Department, malaria vaccine initiative, and other malaria stakeholders, need to undertake for optimal acceptance and utilization of the vaccine. Based on the findings the following recommendations can be made:

- The communication strategy should clarify the questions and expectations raised by stakeholders prior to or parallel with the introduction of the malaria vaccine in lay man's language to avoid any misconceptions about the anticipated malaria vaccine.

- Issues on religion, ethnicity, occupation and region should be considered for the designing of culturally based interventions to increase the acceptability and effectiveness of vaccine programmes.

\begin{abstract}
Authors' contributions
SM made a substantial contribution in the designing of the study, conception of the paper, supervision of the field work, analysis of the qualitative data, interpretation of the findings and drafting of the manuscript. AK assisted in the supervision of the field work and in the analysis of the qualitative data. SM and $A E$ analyzed the quantitative data. JL, SK, SA, IR, and AA provided inputs in the conception and design of the study. JL, ES, IR, SA, SK, MT provided substantial inputs to the paper. All authors, read, revised and approved the final manuscript. All authors read and approved the final manuscript.
\end{abstract}

\footnotetext{
Author details

${ }^{1}$ Ifakara Health Institute (IHI), P.O. Box 78373, Dar es Salaam, Tanzania.

${ }^{2}$ ISGlobal, Barcelona Centre International Health Research (CRESIB), Hospital Clínic, Universitat de Barcelona, Barcelona, Spain. ${ }^{3}$ Health Economics Group, Department of Infectious Disease Epidemiology, School of Public Health, Imperial College London, London, UK. ${ }^{4}$ Mwanza Centre, National Institute for Medical Research Institute (NIMR), Dar es Salaam, Tanzania. ${ }^{5}$ Swiss Tropical and Public Health Institute, Basel, Switzerland.
}

\section{Acknowledgements}

The researchers extend a sincere appreciation to the study participants for their time and valuable information which has been useful in the accomplishment of this study. The work of the field team which was supervised by the scientists from the Ifakara Health Institute $(\mathrm{IHI})$ is highly appreciated. We are grateful to the local leaders and the District Medical Officers (DMOs) at the respective study districts for their support and permissions to conduct studies in their premises. Our sincere appreciation goes to Dr. Mwele Malechela the director of Tanzania National Medical Research Institute, Dr. Antonneite Ba-Nguz; previously worked for PATH-MVI and Dr. Dafrossa Lyimo the director of Immunization department in Tanzania for their inputs which they provided from the conception of this study. We also appreciate the inputs of Dr. Mary Mwangome from IHI. We are thankful to Ms. Hadija Mlege from IHI for coordinating the field logistics. We would also like to extend our appreciation to the PATH Malaria Vaccine Initiative for funding the study.

\section{Competing interests}

The authors declare that they have no competing interests.

Received: 11 June 2015 Accepted: 3 March 2016

Published online: 05 April 2016

\section{References}

1. Tanzania Commission for AIDS, Zanzibar AIDS Commission, National Bureau of Statistics, Office of the Chief Government Statistician, and ICF International. Tanzania HIV/AIDS and Malaria Indicator Survey 2011-12. Dar es Salaam; 2012.

2. Ministry of Health and Social Welfare. National Malaria guideline for Malaria diagnosis and treatment. Dar es Salaam. National Malaria Control Programme; 2008.

3. WHO. World Malaria Report 2008. Geneva: World Health Organization; 2008.

4. National Bureau of Statistics (NBS) and ICF Macro. Tanzania Demographic and Health Survey 2010. Dar es Salaam; 2010.

5. Wongsrichanalai C, Meshnick SR. Declining artesunate-mefloquine efficacy against falciparum malaria on the Cambodia-Thailand border. Emerg Infect Dis. 2008;14:716-9.

6. Baume CA, Reithinger R, Woldehanna S. Factors associated with use and non-use of mosquito nets owned in Oromia and Amhara regional states, Ethiopia. Malar J. 2009;8:26.

7. de Quadros CA. History and prospects for viral disease eradication. Med Microbiol Immunol. 2002;191:75-81.

8. Agnandji ST, Lell B, Soulanoudjingar SS, Fernandes JF, Abossolo BP, Conzelmann C, et al. First results of phase 3 trial of RTS, S/AS01 malaria vaccine in African children. NEJM. 2011;365:1863-75.

9. Agnandji ST, Lell B, Fernandes JF, Abossolo BP, Methogo B, Kabwende $A L$, et al. A phase 3 trial of RTS, S/AS01 malaria vaccine in African infants. NEJM. 2012;367:2284-95.

10. The RTS,S Clinical, Trials Partnership. Efficacy and safety of the RTS, S/ AS01 malaria vaccine during 18 months after vaccination: a phase 3 randomized, controlled trial in children and young infants at 11 African sites. PLoS Med. 2014;11:e1001685

11. Asante KP, Abokyi L, Zandoh C, Owusu R, Awini E, Sulemana A, et al. Community perceptions of malaria and malaria treatment behaviour in a rural district of Ghana: implications for artemisinin combination therapy. BMC Public Health. 2010;10:409.

12. WHO. Department of Immunization, Vaccines, Biologicals: vaccine introduction guidelines: adding a vaccine to a National Immunization Programme: decision and implementation. Geneva: World Health Organization; 2005.

13. Febir LG, Asante KP, Dzorgbo DB, Senah KA, Letsa TS, Owusu-Agyei S. Community perceptions of a malaria vaccine in the Kintampo districts of Ghana. Malar J. 2013;12:156.

14. Ojakaa DI, Ofware P, Machira YW, Yamo E, Collymore Y, Ba-Nguz A, et al. Community perceptions of malaria and vaccines in the South Coast and Busia regions of Kenya. Malar J. 2011;10:14.

15. www.malariavaccine.org/files/MVIfactsheet. Accessed 12 May 2012. 
16. Kabir M. Knowledge, perception and beliefs about childhood immunization and attitude towards uptake of poliomyelitis immunization in a northern Nigerian village. Ann Niger Med. 2005;1:21-6.

17. Romore I, Ali A, Semali I, Mshinda H, Tanner M, Abdulla S. Assessment of parental perception of malaria vaccine in Tanzania. Malar J. 2015;14:355.

18. Strauss A. Qualitative analysis for social scientists. Cambridge: Cambridge University Press; 1987.

19. United Republic of Tanzania. Immunization and Vaccine Development program (2014-18). Communication strategy for routine Immunization.

20. Vogt WP. Dictionary of statistics and methodology: A non technical guide for the social sciences. London: Sage publications; 1999

21. Halcomb E, Davidson P. Is verbatim transcription of interview data always necessary? Appl Nurs Res. 2006;19:38-42

22. www.qsrinternational.com/products_nvivo-mac.aspx. Accessed 26 Apr 2014.

23. Spencer L, Ritchie J, O'Connor W. Analysis: practices, principles, processes. In: Ritchie J, Lewis J, editors. Qualitative research practice: a guide for social science students and researchers. Thousand Oaks: Sage Publications; 2007.

24. Crommett M. Confronting religion: perceptions and health-seeking behaviors of devout adolescents when faced with a sexually transmitted infection in Ghana. GUJHS. 2008;5:1.

25. Shaikh B, Hatcher J. Health seeking behaviour and health service utilization in Pakistan: challenging the policy makers. J Public Health. 2004;27:49-55.
26. Marlow LAV, Wardle J, Forster AS, Waller J. Ethnic differences in human papillomavirus awareness and vaccine acceptability. J Epidemiol Community Health. 2009;63:1010-5.

27. Wombwell E, Fangman MT, Yoder AK, Spero DL. Religious barriers to measles vaccination. J Community Health. 2015;40:597-604.

28. Jackson JD. Structural characteristics of norms. In: Steiner ID, Fishbein M, eds. Current studies in social psychology; 1965. p. 301-9.

29. Favin M, Steinglass R, Fields R, Banerjee K, Sawhney M. Why children are not vaccinated: a review of the grey literature. Int Health. 2012;4:229-38.

30. Stanton BF. Assessment of relevant cultural considerations is essential for the success of a vaccine. J Health Popul Nutr. 2004;22:286-92.

31. Mtenga S, Masanja I, Mamdani M. Strengthening national capacities for researching on social determinants of health $(\mathrm{SDH})$ towards informing and addressing health inequities in Tanzania. Int J Equity Health. 2016;15:23.

32. WHO. A conceptual framework for action on the social determinants of health 2010. Geneva: World Health Organization; 2008.

33. Mtenga S, Pfeiffer C, Merten S, Mamdani M et al (2015) Prevalence and social drivers of HIV among married and cohabitating heterosexual adults in south-eastern Tanzania: analysis of adult health community cohort data. Glob Health Action 8:2894

34. Nasiru S-G, Aliyu GG, Gasasira A, Aliyu MH, Zubair M, Mandawari SU, et al. Breaking community barriers to polio vaccination in northern Nigeria: the impact of a grass roots mobilization campaign (Majigi). Pathog Glob Health. 2012;106:166-71.

\section{Submit your next manuscript to BioMed Central and we will help you at every step:}

- We accept pre-submission inquiries

- Our selector tool helps you to find the most relevant journal

- We provide round the clock customer support

- Convenient online submission

- Thorough peer review

- Inclusion in PubMed and all major indexing services

- Maximum visibility for your research

Submit your manuscript at www.biomedcentral.com/submit
(O) BioMed Central 